\title{
Uma Teoria Naturalista da JustificaÇão das Crenças NA EPISTEMOlogia DE DAVId HuME
}

\author{
Claudiney José de Sousa
}

\begin{abstract}
One of the first difficulties in interpreting Hume's epistemological writings concerns precisely the meaning of the words 'knowledge' and 'belief'. In this article it is shown, initially, how, from a humean point of view, the traditional epistemic criterion to define 'knowledge' and 'belief' appears very restrictive. Hume's theory of causal belief is then briefly reviewed in the light of epistemological naturalism of the Michael J. Costa and Louis E. Loeb. Finally, it is submitted that the examination of all these topics lends support to the Hume's naturalistic theory of justification of beliefs.
\end{abstract}

Keywords: Causal beliefs; knowledge; theory of justification; naturalism; epistemological naturalism.

\section{Introdução}

No diálogo Teeteto (ou Da Ciência), Platão define conhecimento como "opinião verdadeira acompanhada de explicação racional" (Teeteto, 201 d) — definição posteriormente reformulada pela tradição analítica de língua inglesa, para a qual a noção mais adequada seria a de "crença verdadeira justificada" (Chisholm 1977). Várias outras análises e tentativas de definição de 'conhecimento' e 'crença' foram feitas após esta sugestão de Platão, quase sempre mantendo a mesma estrutura fundamental. Por isso, esta definição ficou conhecida como "definição tradicional de conhecimento" ou "concepção apriorista de conhecimento", para a qual a noção de 'crença' ocupa mero papel coadjuvante — sem status epistêmico.

Veremos que em seu Tratado da Natureza Humana ${ }^{1}$ Hume discorda totalmente desta definição tradicional. Sua divergência com a antiga concepção está centrada no conceito de crença. Diferentemente da concepção apriorista, Hume atribui à crença importante estatuto epistêmico, sem perder de vista questões relativas à normatividade e à justificação do conhecimento. A diferença é que Hume empreenderá uma reformulação nas distinções normativas e nos conceitos básicos de sua epistemologia. Embora se afaste da antiga concepção em muitos aspectos, Hume ainda preserva daquele empreendimento a ideia de que a epistemologia não deve abrir mão de sua tarefa normativa. A justificação epistêmica continua sendo a marca essencial de sua teoria do conhecimento. Se antes diríamos que uma crença obtém o status de justificada na medida em que atinge o nível de conhecimento, em Hume diremos que essa mudança de condição epistêmica é dispensável — e mesmo impossível — pois

Principia 18(2): 227-241 (2014).

Published by NEL — Epistemology and Logic Research Group, Federal University of Santa Catarina (UFSC), Brazil. 
'crença' e 'conhecimento' caracterizam âmbitos epistêmicos bem distintos. Em Hume, crenças podem ser em si mesmas justificadas ou não. Mas qual o critério estabelecido por Hume para essa justificação? Se antes tínhamos a explicação racional, que poderia conferir ou não a um estado de nível inferior (opinião ou crença verdadeira) o caráter de justificada, o que temos agora? Ainda há uma tarefa para a razão na teoria da justificação humeana? Em Hume ainda falamos da mesma 'justificação tradicional'?

Alguns comentadores contemporâneos procuraram responder estas questões levando a sério a ideia de que há, em Hume, uma teoria da justificação epistêmica. Acreditam que podemos encontrar, em suas obras, muitos argumentos em favor da tese de que ele teria uma teoria da justificação das crenças e, mais do que isso (o que seria ainda mais surpreendente aos olhos da interpretação apriorista), Hume teria defendido uma teoria naturalista da justificação das crenças. Para esses comentadores, Hume faz distinções básicas entre tipos de crenças e diferentes mecanismos de formação de crenças, classificando-os como justificados ou não. Para tanto, empreendem a difícil tarefa de mostrar como estão dispostos, nessa teoria, os conceitos de causa e efeito, imaginação, hábito, ficção, associação, razão etc. - muitos deles sem qualquer credencial epistêmica para o antigo empreendimento epistemológico. Procuram esclarecer qual o lugar reservado por Hume ao conceito de justificação epistêmica, apesar das críticas a um suposto anacronismo das referidas teses, que teriam sido influenciadas pelos debates epistemológicos contemporâneos. Michael J. Costa e Louis E. Loeb são dois dos principais defensores desta concepção nas interpretações sobre a epistemologia de Hume. Nas próximas páginas analisaremos, resumidamente, a teoria das crenças causais de Hume e avaliaremos o alcance das propostas de Costa e Loeb sobre uma possível justificação naturalista para estas crenças.

\section{A natureza das crenças causais na epistemologia de Hume}

A primeira tarefa de Hume em sua teoria da crença (T. 1.3.7 e EHU. 5.22) é estabelecer a natureza da crença a partir de duas etapas distintas: i) mostrar que a diferença entre crença e ficção não pode estar numa ideia adicional acrescentada à ideia a que damos assentimento e ausente naquela que é mera ficção. A diferença entre a simples concepção da existência de um objeto e a crença nesse objeto só pode estar na maneira como o conhecemos (T. 1.3.7.1-2 e EHU. 5.10-11); ii) mostrar que a noção de crença não diz respeito às relações de ideias, em que somos necessariamente determinados a concebê-las de uma maneira particular (é impossível pensar algo contrário a uma demonstração). A noção de crença diz respeito apenas ao âmbito das questões de fato e existência, em que ambos os lados da questão são igualmente

Principia 18(2): 227-241 (2014). 
possíveis. Neste caso, a crença produz uma diferença entre a concepção a que damos nosso assentimento e aquela de que discordamos, na medida em que muda a maneira como as concebemos. Ela altera essas ideias ao aumentar ou diminuir sua força e vividez, ou seja, ao dar às ideias uma força e vividez adicionais mediante uma relação com uma impressão presente (T. 1.3.7.3-5 e EHU. 5.11). Daí a primeira definição humeana de crença no Tratado: "UMA IDEIA VÍVIDA RELACIONADA OU ASSOCIADA COM UMA IMPRESSÃO PRESENTE" (T. 1.3.7.5, maiúsculas do autor).

$\mathrm{Na}$ Investigação, embora expresse a dificuldade de definir esse "sentimento", Hume arrisca, mesmo assim, uma primeira definição muito próxima daquela oferecida no Tratado, dizendo que "a crença nada mais é que uma concepção mais vívida, vigorosa, enérgica, firme e constante, de um objeto, do que jamais seria possível obter apenas pela imaginação" (EHU. 5.12), um ato mental que torna as realidades mais presentes à mente que as ficções da imaginação. Tendo em vista estas definições, Hume considera que nossas inferências causais (um dos elementos mais importantes de sua concepção epistemológica) são determinadas não pela razão, mas pelo costume ou um princípio de associação (a impressão de um objeto presente gera uma ideia ou crença no objeto constantemente associado a ele) (T. 1.3.7.6). Isso mostra que crença difere de ficção não na natureza ou na ordem de suas partes, mas na maneira como é concebida e sentida pela mente; ela é apenas essa maneira particular - gerada pelo hábito - de formar uma ideia, que nos permite distinguir, pela vivacidade, o juízo das meras ficções da imaginação (T. 1.3.7.7).

Hume acrescentará que a diferença entre ficção e crença não reside apenas nos graus de força e vivacidade, complementando essa explicação em T. 1.3.8, T. 1.3.9 e T. 1.3.10, no Apêndice do Tratado e na Investigação. Em T. 1.3.7 havia enfatizado que o sentimento especial que constitui a crença é apenas a força e vivacidade das ideias, mas reforça essa concepção em T. 1.3.8, a partir de uma máxima da natureza humana, segundo a qual "quando uma impressão qualquer se nos torna presente, não apenas transporta a mente para as ideias a ela relacionadas, mas igualmente comunica-lhes parte de sua força e vivacidade" (T. 1.3.8.2; itálicos do autor), propondo também alguns mecanismos (referentes aos casos de associação por contiguidade, semelhança e causação) para apoiá-la.

Na Investigação, Hume analisa a possibilidade de mostrar que também em outras relações (semelhança, contiguidade e causação) a mente alcançaria uma concepção mais forte e constante dos objetos correlativos, como já havia feito no Tratado. Na verdade, o que Hume investiga aqui é se estes princípios são capazes de levar a mente a uma concepção mais forte e estável dos objetos relacionados, assim como ocorre com a crença mediante a relação de causa e efeito. Ao fazê-lo o autor constata que, em todos estes casos, a crença no objeto é sempre pressuposta. Situação que não se aplica à causalidade. Ela não pressupõe a crença, uma vez que é o ponto de partida para a crença. É ela quem gera a crença. Segundo Hume, sem a crença os objetos não 
teriam nenhuma influência sobre a mente. Além disso, para chegar a essa conclusão é preciso estar ciente de que a crença é o resultado da causação (EHU. 5.18-20).

Hume parece ter revisto a concepção de que a vivacidade é o critério exclusivo da crença. É possível perceber que em T. 1.3.10.10 e em EHU. 5.11.13, Hume passa a caracterizar a crença como uma sensação especial, embora mantenha a vivacidade como noção central, porém não mais exclusiva. Além de estabilidade e intensidade, Hume passa a exigir que esse sentimento surja da conjunção regular de fenômenos, ou seja, que tenha uma base experimental (Chibeni 2006, p.1-17).

Segundo Hume, "O sentimento de crença não passa de uma concepção mais intensa e estável do que a que acompanha as meras ficções da imaginação, e [...] essa maneira de conceber surge da conjunção costumeira do objeto com algo presente à memória ou aos sentidos" (EHU. 5.13; itálico do autor).

Uma vez que a razão é insuficiente para oferecer critérios últimos para o conhecimento provindo da experiência, Hume não teria outra alternativa a não ser examinar as circunstâncias de formação da crença e encontrar nelas próprias seu critério para nosso assentimento. Hume conclui, dessa forma, que "todo raciocínio provável não é senão uma espécie de sensação [feeling]" (T. 1.3.8.12) ou uma ideia que me atinge de modo mais forte. Hume lembra, ainda, que todo esse processo é possível por conta do hábito ou costume. Ele é a única conexão ou princípio que podemos descobrir entre os objetos. Mediante esse princípio, a experiência passada atua sem que tenhamos tempo para refletir (T. 1.3.8.12-13).

Sempre que um objeto qualquer é apresentado à memória ou aos sentidos, ele imediatamente, pela força do hábito, leva a imaginação a conceber o objeto que lhe está usualmente associado, e essa concepção é acompanhada de uma sensação ou sentimento que difere dos devaneios soltos da fantasia (EHU. 5.11).

Por isso, Hume dirá que a crença é uma concepção de um objeto "mais vívida, vigorosa, enérgica, firme e constante do que jamais seria possível obter apenas pela imaginação" (EHU. 5.12); um ato mental que torna as realidades mais presentes a nós que as ficções, dando-lhes peso e influência maiores sobre o pensamento. Dessa forma, mesmo com toda liberdade e poder de alterar nossas ideias, a imaginação sozinha jamais poderia gerar crença, porque ela "não consiste na natureza particular ou ordem de nossas ideias, mas na maneira como são concebidas e no sentimento que trazem à mente" (EHU. 5.12; itálicos do autor).

\section{A legitimidade das crenças causais}

Segundo Michael J. Costa é possível defender uma teoria da justificação das crenças na epistemologia de Hume. Na visão do comentador Hume teria empreendido uma 
série de refinamentos em suas considerações sobre as crenças em seus trabalhos: i) procedendo a uma rígida classificação e hierarquização de crenças e ii) esclarecendo as exigências que se deve fazer ao sujeito cognoscente em diferentes níveis epistêmicos. Contudo, vale lembrar que Costa toma como exemplo apenas o caso das crenças causais, o que não significa que muitas de suas observações também não possam ser aplicadas a outros tipos de crenças estudadas por Hume: a crença na existência de corpos, por exemplo. Partiremos de uma passagem do artigo "Hume and Justified Belief", em que Costa sintetiza a questão.
A associação mediante causa e efeito é o modo normal ou padrão em que as crenças são formadas. Crenças podem surgir de outros modos, mas se- riam algo como aberrações ou anomalias. O paradigma ou caso padrão de formação de crença é aquele em que a crença se segue involuntariamente e imediatamente a alguma impressão por conta do hábito produzido pela experiência de um grande número de casos, nos quais, os objetos que se assemelham [...] foram associados mediante causa e efeito (Costa 1995, p.176; itálicos do autor).

Hume admite que as crenças podem ser produzidas de vários modos diferentes, mas ele não admite que todas possam ser consideradas legítimas. Há crenças que podem ser consideradas normais ou crenças-padrão porque tem origem em princípios permanentes, irresistíveis e universais da imaginação (T. 1.4.4.1). Que mecanismos de formação de crenças tem essas características? Hume mostra que não podem ser mecanismos que tem como fundamento princípios fracos, inconstantes e incertos de associação (T. 1.4.4.1). Por isso, Costa acredita que "Hume toma a associação de causa e efeito como o único modo de formação de crenças justificadas" (Costa 1995, p.177). Um dos fundamentos para essa concepção estaria no fato de "Hume identifica[r] as conclusões de causa e efeito com aquelas da 'razão"' (Costa 1995, p.177). Costa nos dá um exemplo retirado da discussão sobre a crença na existência de corpos, mas que serviria também para o caso das crenças causais.

Ele [Hume] rotula as crenças sobre a existência independente e contínua dos corpos de vários modos como 'ficções', 'ilusões' e 'falácias' [...]. Isso não porque falte a elas justificação dedutiva, ou porque elas envolvam absurdos lógicos, mas porque elas estão em conflito com conclusões derivadas dos 'raciocínios' de causa e efeito (Costa 1995, p.177).

Além desse critério, Hume pensa que precisamos saber se todos os Mecanismos de Formação de Crenças (que Costa simboliza com MFBs) dentro de sua Teoria da Justificação das Crenças (que simboliza com HJB), derivados de associações mediante causa e efeito, são justificados — outro nível de refinamento de sua teoria. Para Costa, Hume reconhece que o funcionamento psicológico dos indivíduos pode variar devido a deficiências naturais, influências do meio social e contingências da cognição humana (sonho, loucura, superstição, histórias fictícias, educação etc). Dessa 
forma, uma primeira exigência de Hume para um mecanismo de formação de crenças justificado (que deverá depois ser refinado) seria, aproximadamente, como se segue:

HJB: um MFB é justificado para $S$ se e somente se $S$ tem um funcionamento associativo padrão (isto é, normal), e se a experiência prévia de $S$ tem MFBs produzidos por princípios de associação de causa e efeito (Costa 1995, p.178).

A teoria da justificação das crenças de Hume, assim concebida, elimina a possibilidade de que os mecanismos de formação de crenças ocorram por conta de mera propensão da imaginação, da fantasia, da ficção ou de qualquer outro meio inconstante e irregular de produção de crenças. Hume pretendia mostrar que os vários mecanismos e processos envolvidos na cognição humana (causa e efeito, hábito, razão, imaginação, ficção etc.) estão ordenados, do ponto de vista epistêmico, de forma hierarquizada. Mais do que isso, Costa mostra que Hume estaria preocupado também em estabelecer distinções e classificações em diferentes níveis epistêmicos, ou seja, que ele faria distinções no conjunto das próprias crenças justificadas. Isso seria necessário na medida em que ele percebe que também estas últimas podem variar, sofrer alterações e mudanças e que o sujeito cognoscente é capaz de perceber essas alterações, fazendo as devidas correções em seu julgamento. Hume teria reconhecido essa limitação cognitiva em vários momentos de suas obras, mas principalmente quando faz suas observações sobre a probabilidade não filosófica em $\mathrm{T}$. 1.3.13. Hume identifica, nesta seção, "certos modos em que a operação natural e normal da associação de causa e efeito não é confiável" (Costa 1995, p.178, itálicos nossos), ou como o próprio Hume afirma: "não tiveram a sorte de obter igual aprovação" (T:1.3.13.1).

Retomemos os quatro casos de probabilidade não filosófica apresentados por Hume em T. 1.3.13 para avaliarmos a sugestão do comentador: i) a força da crença pode variar de acordo com a vivacidade da impressão (T.1.3.13.1); ii) a força da crença pode variar de acordo com a duração do tempo desde a última experiência da conjunção de causa e efeito (T. 1.3.13.2); iii) a crença pode ser enfraquecida se há uma longa cadeia causal entre a causa e o efeito (T.1.3.13. 3-6); iv) as crenças podem ser produzidas por impressões que não se assemelham aos objetos da experiência passada de tipo causalmente relevante (T. 1.3.13.7-8). Há probabilidades que são aceitas e probabilidades que são rejeitadas pelos filósofos porque apenas algumas constituem fundamentos razoáveis para a crença. Também em EHU. 6 Hume mostrará que a crença está associada à noção de probabilidade. A este respeito Conte faz um importante esclarecimento, citando como exemplo o que poderíamos entender como legitimidade da crença na conexão causal, em detrimento de sua "nãojustificação demonstrativa":

Principia 18(2): 227-241 (2014). 
A ocorrência mais provável de um evento no futuro está associada à sua ocorrência mais frequente no passado. Essa ocorrência passada fortalece a crença na ocorrência futura do evento, dado que a ele se associa uma maior probabilidade de que venha a acontecer. Para Hume, a crença na conexão causal, embora permaneça irremediavelmente injustificada e injustificável nos termos de uma razão demonstrativa, é, no entanto, um legítimo produto da imaginação assistida pelo hábito (Conte 2010, p.222; itálicos nossos)

Tendo isso em vista, Costa argumentará que este é novamente um momento em que Hume está propondo um refinamento de sua teoria da justificação epistêmica. Que significa isso? Significa que, em face dos modos não confiáveis da operação das associações de causa e efeito, Hume identifica e ressalta os modos que poderíamos chamar de confiáveis, ou seja, "admite [em sua teoria] a probabilidade filosófica e rejeita a influência da probabilidade não filosófica" (Costa 1995, p.179). Outra distinção importante feita nos parágrafos finais de T. 1.3.13 seria aquela entre 'julgamentos da razão' e 'crenças puramente instintivas': apenas as primeiras operariam por meio de regras.

Hume nos dá um indício de como executar isto notando que a diferença entre julgamentos da razão e crenças produzidas puramente por instintos está em que a aplicação das regras gerais está tipicamente envolvida no caso dos julgamentos. Ambos os tipos de crenças surgem do funcionamento psicológico padrão e do hábito [...]. A diferença está em que o hábito [...] opera por meio de regras gerais no caso dos julgamentos (Costa 1995, p.180).

No caso das crenças causais, os julgamentos mediante regras gerais seriam semelhantes a inferências de primeira ordem, que podem ser confrontadas com inferências de ordem superior. O filósofo faria uma reflexão sobre as primeiras e julgaria sobre a probabilidade de sua verdade podendo, assim, aceitá-la ou rejeitá-la. O filósofo, ou o homem de experiência e temperamento, aceitaria apenas as crenças justificadas (crenças de segunda ordem). A prevalência de um tipo de inferência ou de outro depende da disposição e do caráter da pessoa. É próprio da inferência de segunda ordem corrigir e regular a inferência de primeira ordem e fixar seus padrões exatos (Costa 1995, p.180). Costa acredita que, com base neste desenvolvimento dos graus de inferência e crença, Hume pretende apresentar um segundo nível de refinamento de sua teoria da justificação das crenças, estipulando novas exigências ao sujeito cognoscente, que poderiam ser expressas, aproximadamente, como se segue:

HJB $\star$ : um MFB é justificado para $S$ se e somente se $S$ tem um funcionamento associativo padrão (isto é, normal) e se as experiências prévias de $S$ têm algum grau de MFB produzido pelo princípio de associação de causa e efeito. Além disso, estes mecanismos não podem ter sido reduzidos abaixo do mínimo de força e vivacidade requeridos para uma crença e $S$ deve ter

Principia 18(2): 227-241 (2014). 
aplicado princípios gerais [...] à sua inferência de primeira ordem (Costa 1995, p.180).

Para Hume, o sujeito cognoscente que tem um funcionamento associativo padrão regula suas crenças e as ajusta de forma apropriada, ou seja, seleciona e elege aquelas crenças que, de acordo com estes critérios, podem ser consideradas confiáveis, aptas para a condução da vida e para a ação. Costa destaca a importância da noção de confiabilidade epistêmica como critério para justificação das crenças em Hume: "a crença é justificada se ela teve um tipo de história causal correta [...] [ou seja] se geralmente produz crenças verdadeiras" (Costa 1995, p.180; itálicos nossos). Desta forma, Costa mostra que os conceitos de crença e justificação tem lugar central na teoria da crença de Hume, agora com papeis bem diferentes daqueles que tinham anteriormente na concepção apriorista.

\section{Equilíbrio e estabilidade epistêmica}

Avaliaremos também uma segunda proposta de interpretação, sobre a teoria naturalista da justificação das crenças em Hume, apresentada por Louis E. Loeb, primeiramente em "Hume on Stability, Justification, and Unphilosophical Probability", de 1995, retomada de forma mais sistemática no livro Stability and Justification in Hume's Treatise, de 2002.

O que talvez cause maior surpresa na perspectiva geral de Loeb sobre este tema, nos dois referidos trabalhos, é que, embora seja uma tentativa de apresentar uma teoria da justificação epistêmica em Hume, ela deriva basicamente das abordagens da psicologia da imaginação apresentadas no Tratado, principalmente aquelas encontradas entre as seções 9 e 13 da terceira parte do primeiro livro. Loeb partirá de detalhes que não só a interpretação tradicional, mas o próprio Hume, pareciam considerar de menor importância para a compreensão de sua epistemologia. Por isso, sua interpretação está em claro conflito com as análises tradicionais segundo as quais Hume teria confundido psicologia e filosofia. Loeb mostra como é possível extrair uma teoria da justificação epistêmica da filosofia Humiana a partir de sua psicologia e elaborar assim uma teoria naturalista da justificação.

Sustento que Hume possui uma teoria naturalista da justificação epistêmica, uma teoria que distingue entre crenças justificadas e crenças não justificadas com referência a uma tendência, dos mecanismos de formação de crenças, a produzir estabilidade psicológica nas crenças (Loeb 2002, p.viii; itálicos nossos).

Loeb acredita, porém, que Hume não teve sucesso completo nessa tentativa de apontar critérios de legitimação de crenças, especialmente porque, segundo ele, a 
tentativa fracassa no caso importante das crenças na existência de corpos. Assim, diz Loeb, "[s]ua teoria naturalista da justificação [...] o conduz [efetivamente] ao resultado pessimista de que nenhuma crença é justificada sob reflexão" (Loeb 2002, p. viii). O trabalho de Loeb nesse livro envolve, então, não apenas a análise e interpretação dos textos de Hume, mas também uma espécie de desenvolvimento e correção da interpretação naturalista da epistemologia de Hume, que tinha sido originalmente desenvolvida por Norman Kemp Smith e que Loeb chama de a interpretação de Kemp Smith $^{2}$ (Loeb 1995, p.111-2 e 2002, p.20-7). A esse respeito Loeb afirma: "Kemp Smith sustenta que Hume tinha uma resposta para o ceticismo em sua doutrina das "crenças naturais" que são "inevitáveis" e "irresistíveis". Isto o leva a formular um sentido em que, para Hume, crenças naturais devem ser aceitas" (Loeb 1995, p.111; itálico nosso). Seria um absurdo ou algo insensato dizer que não devemos sustentar essas crenças, porque simplesmente não podemos evitá-las, não é uma escolha nossa. Contudo, contesta Loeb: "A interpretação de Kemp Smith não é capaz de explicar como algumas crenças irresistíveis podem deixar de ser justificadas" (Loeb 1995, p.111).

Loeb apresenta uma proposta de interpretação que preencheria esta lacuna deixada por Kemp Smith; uma concepção que esclarece porque a "irresistibilidade" ou a "inevitabilidade" não são condições suficientes para a justificação. O próprio Hume teria considerado, segundo ele, que "crenças irresistíveis não são justificadas quando resultam de desequilíbrio (ou talvez, quando resultam de mecanismos que tendem a produzir desequilíbrio)" (Loeb 1995, p.112, itálico nosso). Neste sentido, a sugestão de Loeb é de que uma análise mais adequada da teoria da justificação epistêmica em Hume deveria estar fundamentada em novos conceitos: basicamente 'equilíbrio' e 'estabilidade'.

Concordo com Kemp Smith que estas propriedades são, em grande medida, psicológicas. Para Kemp Smith, entretanto, a propriedade básica é a irresistibilidade; em minha interpretação é a estabilidade. Esta diferença é importante (Loeb 2002, p.22).

Na interpretação de Kemp Smith a epistemologia de Hume teria uma carga negativa; não explicaria porque devemos aceitar crenças irresistíveis e inevitáveis, nem explicaria a força normativa dos julgamentos epistêmicos. Já a interpretação de Loeb afirma que "Hume não apenas delimita classes de crenças que devemos aceitar em termos naturalistas, mas também fornece uma explicação positiva de nossas obrigações (obligations) epistêmicas para aceitá-las — com referência ao desejo de aliviar o desconforto" (Loeb 2002, p.22; itálicos nossos). Hume teria explicado isso no Tratado ao defender a ideia de que diante de estados de desconforto, buscamos estados doxásticos que são estáveis. A atribuição de valor a estes estados doxásticos teria um fundamento naturalista. "Para Hume, a obrigação epistêmica é naturalizada uma 
vez que deriva da força motivacional de sentir desconforto em condições doxásticas instáveis" (Loeb 2002, p.22).

Loeb propõe uma comparação entre julgamentos epistêmicos e julgamentos morais em Hume para esclarecer o que ele entende por 'estabilidade', bem como a ideia de que temos uma motivação natural para buscá-la. Em Hume a obrigação moral requer a atuação de alguma paixão ou motivo, em geral, a busca do prazer e a aversão à dor. Os julgamentos ou distinções morais estariam fundados em prazeres ou dores. Por isso, Loeb conclui: "Na visão de Hume, tanto a obrigação epistêmica quanto a obrigação moral derivam da motivação na forma de tipos particulares de sentir desconforto e satisfação" (Loeb 2002, p.23; itálicos nossos). Os mecanismos de formação de crenças não-justificados produzem crenças conflitantes que, por sua vez, geram desconforto. Isso conduz à noção de que há uma motivação positiva para aceitar mecanismos estáveis que produzem conforto e alívio das tensões psicológicas. A interpretação de Kemp Smith não explicaria essas origens nem as avaliações epistêmicas em casos particulares, por isso a irresistibilidade não é uma condição nem necessária nem suficiente para a justificação das crenças. Não é uma condição necessária porque Hume mostra que há crenças que são estáveis, mas que não são irresistíveis, por exemplo, quando admite que o costume pode produzir expectativas sobre questões de fato não observadas com base em uma única observação (T. 1.3.8.14). Hume explica que isso é possível por conta das crenças de segunda ordem; crenças de ordem superior que sustentam crenças baseadas em casos singulares, com a condição de que "este seja feito criteriosamente e após uma cuidadosa exclusão de todas as circunstâncias estranhas e supérfluas" (T. 1.3.8.14). ${ }^{3}$

A irresistibilidade também não é uma condição suficiente porque Hume mostra que há crenças que são irresistíveis, mas que não são justificadas, por exemplo, quando afirma que há julgamentos que sofrem variações nos graus de confiança ou variações no sentimento devido à simpatia etc. (T. 1.3.13.8-9, T.1.4.3.11). Hume teria feito correções nestas espécies de julgamento - algo para o qual Kemp Smith não deu muita atenção (Loeb 2002, p.23). A irresistibilidade não seria um bom critério para a justificação porque há crenças incluídas neste critério, mas que não podem ser consideradas justificadas. Parece-nos que, para Loeb, a noção central na teoria da justificação de Hume é 'estabilidade psicológica'.

Estabilidade é uma propriedade disposicional, a tendência de um estado doxástico para permanecer estável, sem mudança. Dois tipos amplos de instabilidade são de interesse para Hume. Primeiro, há a instabilidade de um estado doxástico devido exclusivamente a características dos mecanismos que produzem ou sustentam o estado [...] [alguns mudam abruptamente; em outros não há fixidez; alguns são fixos, mas tem tendência a mudar gradualmente], segundo, há a instabilidade de um estado doxástico próprio do desequilíbrio no conjunto dos estados doxásticos do qual ela é um membro

Principia 18(2): 227-241 (2014). 
(Loeb 1995, p.101-2).

Os mecanismos de formação de crenças que podem gerar estados de crenças mais ou menos fixos e estáveis, aos quais ele se refere, são a percepção, a memória, a ficção, a imaginação etc. Estes mecanismos podem tanto produzir quanto sustentar estes estados. Por outro lado, os próprios estados doxásticos podem gerar equilíbrio ou desequilíbrio. Por isso, Loeb afirma que

Um estado doxástico que sofre de falta de fixidez não merece ser chamado de uma crença. Ele [Hume] pensa, de certa forma, que um estado doxástico (seja ou não qualificado como uma crença) que sofre de desequilíbrio, não merece ser chamado justificado (Loeb 1995; p.102; itálicos do autor).

Essa noção humeana de justificação teria sido desenvolvida, segundo Loeb, em dois estágios: um construtivo e outro destrutivo. No estágio construtivo Loeb entende que Hume teria feito o que podemos chamar de "distinções pré-teóricas entre crenças justificadas e crenças não justificadas" (Loeb 1995, p.102). Neste estágio Hume utiliza sua teoria e suas noções sobre os mecanismos de formação de crenças para explicar as distinções pré-teóricas e tem algum sucesso em fazê-lo. Já no estágio destrutivo, o mesmo procedimento geraria "a conseqüência de que nenhuma crença resulta justificada e, consequentemente, que as distinções pré-teóricas não podem ser sustentadas com referência à teoria como um todo" (Loeb 1995, p.102).

Talvez o aspecto mais significativo na tese dos dois estágios, levantada por Loeb, seja o posicionamento de Hume diante da incompatibilidade entre eles. Segundo Loeb, "em face desta conclusão, Hume opta por manter a teoria da justificação e abandonar as distinções pré-teóricas" (Loeb 1995, p.102). O que mostraria que há uma tensão em sua tentativa de estabelecer as referidas distinções. Haveria avaliações ambivalentes e mesmo contraditórias no nível das distinções normativas préteóricas. Por isso, existe também a dificuldade de se estabelecer uma teoria da justificação inteiramente articulada, conforme poderíamos encontrar em outros autores. Se Hume abandona as distinções, como pode sustentar uma teoria da justificação?

Segundo Loeb, Hume teria chegado à conclusão de que nenhuma crença pode ser justificada de forma reflexiva. Na conclusão do Tratado, em T.1.4.7, Hume teria demonstrado certa melancolia e descontentamento com os resultados obtidos porque teria percebido que "nossos mecanismos de formação de crenças inevitavelmente tendem a produzir conjuntos de crenças que estão em desequilíbrio" (Loeb 1995, p.103). Isso caracterizaria, resumidamente, um primeiro estágio, que Loeb denomina de estágio destrutivo da teoria da justificação de Hume.

Na conclusão do Tratado (T.1.4.7), Hume afirma que as deficiências de nossas faculdades e a falta de critérios para distinguir entre a verdade e a falsidade geram uma insegurança com relação a seu projeto. Não está seguro nem mesmo dos 
mais exatos raciocínios, já que, segundo ele, somos instruídos apenas pela experiência e pelo hábito, que atuam juntamente sobre a imaginação. Afirma que todas as faculdades humanas (memória, sentidos e entendimento) parecem estar fundadas na imaginação, mas que também esta faculdade parece ser inconstante e falaciosa; ela nos levaria a contradições. Nos faz "raciocinar" partindo de causas e efeitos, por exemplo, mas também nos convence da existência contínua dos objetos externos. Segundo Hume, se investigarmos os primeiros princípios do entendimento humano, nos sentimos ainda mais desencorajados. Quando buscamos pela conexão das causas ou princípio de união, ficamos desapontados ao saber que há apenas uma conexão em nós mesmos; uma determinação da mente adquirida pelo costume. O vulgo não se dá conta dessas deficiências e cede às ilusões da imaginação. Assim, é difícil definir até que ponto devemos ou não seguir esse princípio, já que suas sugestões são contrárias umas às outras e nos levam a erros e obscuridades. Por outro lado, não podemos rejeitá-las e seguir apenas o entendimento que, quando age sozinho, destrói-se a si mesmo. Assim, a imaginação continua sendo o único meio de nos salvarmos desse ceticismo (T. 1.4.7.3-6).

Quanto ao segundo estágio - o estágio construtivo - Loeb procura apresentar basicamente duas coisas: que Hume teria um compromisso com distinções epistêmicas em sua obra e que um caso exemplar estaria em suas discussões sobre a probabilidade nas seções 11, 12 e 13 da terceira parte do primeiro livro do Tratado. Para Loeb, estas seções nos fornecem uma espécie de 'estudo de caso' ou até mesmo um 'conjunto de estudos de caso interligados'. Algumas questões podem nos ajudar a pontuar esta dificuldade: como Loeb entende o tratamento dado por Hume ao tema da probabilidade não-filosófica? Por que a análise da probabilidade seria um modelo para entendermos sua teoria naturalista da justificação das crenças?

Loeb entende que "as probabilidades não-filosóficas derivam do desequilíbrio que surge na memória e na inferência causal, mas que são elimináveis" (Loeb 1995, p.103). O resultado do estudo sobre a probabilidade é que ele exigiria o apelo de Hume a regras gerais: "crenças de segunda ordem que servem para desestabilizar ou para estabilizar sistemas de crenças de primeira ordem" (Loeb 1995, p.103).

De acordo com meu sistema, todo raciocínio é apenas efeito do costume; e o único efeito do costume é avivar a imaginação, produzindo em nós uma concepção forte de um determinado objeto. Pode-se, portanto, concluir que nosso juízo e nossa imaginação nunca podem ser contrários, e que a ação do costume sobre essa última faculdade é incapaz de fazê-la opor-se à primeira. A única forma de se eliminar essa dificuldade é admitir a influência de regras gerais (T. 1.3.18.11).

Principia 18(2): 227-241 (2014). 


\section{Conclusão: o compromisso de Hume com a normatividade epistêmica}

A partir das contribuições de Costa e Loeb para a análise da teoria da justificação de Hume gostaríamos de concluir esta discussão apresentando dois aspectos da epistemologia de Hume que, em nossa concepção, ilustram muito bem seu compromisso com a normatividade e a justificação epistêmica de nossas crenças. O primeiro deles é a noção de 'regras gerais' apresentado em T. 1.3.13.12. Hume entende que as regras gerais se formam segundo a natureza de nosso entendimento e de nossos juízos sobre os objetos. É por meio delas que podemos distinguir circunstâncias acidentais de causas eficientes. É preciso considerar, também, que estas regras gerais podem opor-se umas às outras. Por exemplo, a primeira influência das regras gerais é fazer com que, diante de um objeto semelhante a uma causa, a imaginação nos leve a uma concepção vívida de seu efeito habitual. Mas, por outro lado, uma segunda influência dessas regras nos mostra que esse ato da mente é de natureza irregular e que destrói os princípios mais bem estabelecidos do raciocínio. Por isso, deve ser rejeitado. Ora uma, ora outra dessas influências prevalece (T. 1.3.13.12).

Outro elemento que ilustra esse compromisso é sua preocupação em distinguir entre mecanismos de formação de crença com base nos graus de evidência. Hume faz distinções epistêmicas em sua teoria da crença e destaca um exemplo destas distinções para ilustrar seu compromisso com a normatividade (a distinção entre provas e probabilidade). Hume afirma em T. 1.3.11 que provas são inferências causais condicionadas por conjunções constantes freqüentemente observadas [...]. Segundo ele, estes "argumentos causais excedem a probabilidade, podendo ser aceitos como uma espécie superior de evidência" [...] "estão inteiramente livres de dúvidas e incerteza" (T.1.3.11.1). O autor mostra, com isso, que tem um compromisso claro em demarcar, em sua teoria, vários graus de evidência.

Com relação à inferência causal podemos destacar ainda uma passagem significativa do final de T.1.4.3.11 ("Da filosofia antiga") em que Hume afirma ser ela um raciocínio correto (just). Na referida seção, Hume está fazendo referência a crenças baseadas na superstição, que podem ser consideradas naturais, mas que não podem ser consideradas corretas e utiliza a expressão 'to justify' para fazer a distinção.

A natureza humana possui uma notável inclinação a atribuir aos objetos externos as mesmas emoções que observa em si própria; e a enxergar em todo lugar aquelas ideias que lhe estão mais presentes. É verdade que essa inclinação se elimina por uma pequena reflexão, e só persiste nas crianças, nos poetas e nos filósofos antigos. [...] Devemos perdoar as crianças, porque tem pouca idade; os poetas, porque admitem seguir, sem reservas, as sugestões de sua fantasia. Mas que desculpa encontraremos para justificar nossos filósofos em uma fraqueza tão evidente? (T. 1.4.3.11; itálicos nossos).

Principia 18(2): 227-241 (2014). 
Estas e outras distinções, realizadas por Hume em vários momentos do Tratado, refletiriam seus compromissos epistemológicos pré-teóricos e sua tentativa de mostrar como sua teoria poderia explicar esses compromissos. O problema, segundo Loeb, é que Hume logo percebe que suas distinções normativas não podem ser sustentadas com referência à sua teoria. As razões para chegar a essa conclusão residem no fato de que ele constata que não podemos atingir um total equilíbrio em nossas crenças (o que talvez fosse o ideal da concepção apriorista, mas não parece ser o de Hume).

De forma bastante modesta Hume reconhece que nossas crenças estão irremediavelmente sujeitas a contradições que geram desequilíbrio. Por isso, Hume decide abandonar as distinções, o que, neste caso não exige um abandono do compromisso com a justificação. Diferentemente da concepção apriorista, sua noção de justificação agora está atrelada a um outro compromisso: a busca por equilíbrio diante do conflito das faculdades ou diante das inevitáveis contradições geradas pelos mecanismos de formação de crenças. Acreditamos que talvez Hume apenas tenha diminuído suas exigências quanto à justificação e a normatividade para colocá-las no nível dos sujeitos epistêmicos reais, com suas limitações cognitivas reais. A busca por equilíbrio e estabilidade das crenças e a escolha daquelas que são mais aptas para a condução da vida e ação é um princípio da natureza humana. Diante do desconforto gerado pelo conflito de crenças, os sujeitos humanos tendem naturalmente à busca por alívio, conforto e tranquilidade em seus julgamentos. ${ }^{4}$

\section{Referências}

Chibeni, S. S. 2006. Hume e as Crenças Causais. In: J. Ahumada, M. Pantalone e V. Rodríguez (eds.) Epistemologia e História de la Ciência, vol. 12. (Seleccion de trabajos de las XVI Jornadas de Epistemologia e História de la Ciência.). Córdoba: Universidad Nacional de Córdoba, pp.143-9.

Chisholm, R. M. 1977. Theory of Knowledge. 2nd. ed. Englewood Cliffs: Prentice Hall.

Conte, J. 2010. A Natureza da Filosofia de Hume. Princípios 17(28): 211-36.

Costa, M. J. 1995. Hume and Justified Belief. In: S. Tweyman (ed.) David Hume: Critical Assessments.1. London and New York: Routledge, pp.144-6.

Hume, D. 2000 [1739]. A Treatise of Human Nature. D. F. Norton and M. J. Norton (eds.), Oxford: Oxford University Press.

— 1999 [1748]. An Enquiry Concerning Human Understanding. T. L. Beauchamp (ed.). Oxford: Oxford University Press.

Lenz, J. W. 1966. Hume's Defense of Causal Inference. Journal of the History of Ideas 19(4): 559-67.

Loeb, L. E. 1995. Hume on Stability, Justification, and Unphilosophical Probability. Journal of the History of Philosophy 33(1): 101-32.

- 2002. Stability and Justification in Hume's Treatise. Oxford: Oxford University Press.

Principia 18(2): 227-241 (2014). 
Monteiro, J. P. 1997. Hume on Singular Experiences. (Translated by Michael Wrigley). Manuscrito 20(2): 123-44.

Platão. 1963. Teeteto, o de la ciência. Trad. José Antonio Miguez, Buenos Aires: Aguilar.

Smith, N. K. 1905. The Naturalism of Hume. Mind 14: 149-73 and 335-47.

—. 1966[1941]. The Philosophy of David Hume: a Critical Study of its Origins and Central Doctrines. New York: St. Martin's Press.

Strawson, P. F. 1985. Skepticism and Naturalism: Some Varieties. New York: Columbia U. P.

Stroud, B. 1977. Hume. Londres: Routledge \& Kegan Paul.

- 1991. Hume's Scepticism: Natural Instincts and Philosophical Reflection. Philosophical Topics 19(10): 271-91.

Claudiney José De Sousa Universidade Estadual de Londrina claudineyuel@hotmail.com

Resumo. Uma das primeiras dificuldades na interpretação dos escritos epistemológicos de David Hume diz respeito precisamente ao significado dos termos 'conhecimento' e 'crença'. Neste artigo mostra-se, inicialmente, como, de um ponto de vista humeano, o critério epistêmico tradicional para definir 'conhecimento' e 'crença' parece muito restritivo. A teoria humeana da crença causal é, então, brevemente exposta e comentada à luz do naturalismo epistemológico de Michael J. Costa e Louis E. Loeb. Por fim, defende-se que o exame desses tópicos dá sustentação à interpretação de uma teoria naturalista da justificação das crenças em Hume.

Palavras-chave: Crenças causais; conhecimento; teoria da justificação; naturalismo epistemológico.

\section{Notas}

${ }^{1}$ A partir daqui utilizaremos apenas 'Tratado' e 'Investigação' para nos referirmos às duas obras básicas para o estudo da epistemologia de Hume. As citações e referências ao Tratado foram retiradas da edição de David Fate Norton and Mary J. Norton, de 2005, e seguirão o seguinte modelo: T.[livro].[parte].[seção].[parágrafo]. As citações e referências à Investigação foram retiradas da edição de Tom L. Beauchamp, de 1999, e seguirão o seguinte modelo: EHU.[seção].[parágrafo].

${ }^{2}$ A primeira referência a esta expressão, no texto de Loeb, aparece em itálico porque o autor faz questão de destacar que ela abrange a interpretação de outros autores, tais como John Lenz (1966), P. F. Strawson (1985) e Barry Stroud (1977 e 1991) que também adotam versões daquela teoria.

${ }^{3}$ Veja detalhes do problema da inferência com base em experiência singulares em Monteiro (1997).

${ }^{4}$ Este texto corresponde à parte da tese de doutorado que submeti ao Instituto de Filosofia e Ciências Humanas da Unicamp em 2012. Foram feitos alguns aperfeiçoamentos e ligeiras alterações. Sou grato, de modo especial, ao meu orientador, prof. Dr. Silvio Seno Chibeni (Unicamp) e ao prof. Dr. Jaimir Conte (UFSC) pelas valiosas contribuições e sugestões. Isso não significa que compartilhem das ideias aqui defendidas.

Principia 18(2): 227-241 (2014). 